\title{
ST-segment resolution as a marker for severe myocardial fibrosis in ST-segment elevation myocardial infarction
}

\author{
Qian Dong ${ }^{1}$, Xuesong Wen², Guanglei Chang ${ }^{1}$, Rui Xia ${ }^{3}$, Sihang Wang ${ }^{3}$, Yunjing Yang ${ }^{1}$, Yi Tao², \\ Dongying Zhang ${ }^{1 *}$ and Shu Qin ${ }^{1 *}$
}

\begin{abstract}
Objective: To investigate the relationship between ST-segment resolution (STR) and myocardial scar thickness after percutaneous coronary intervention (PCI) in patients with ST-segment elevation myocardial infarction (STEMI).

Methods: Forty-two STEMI patients with single-branch coronary artery stenosis or occlusion were enrolled. STsegment elevations were measured at emergency admission and at $24 \mathrm{~h}$ after PCl. Late gadolinium-enhanced cardiac magnetic resonance imaging (CMR-LGE) was performed 7 days after PCI to evaluate myocardial scars. Statistical analyses were performed to assess the utility of STR to predict the development of transmural (> 75\%) or non-transmural $(<75 \%)$ myocardial scars, according to previous study.

Results: The sensitivity and specificity of STR for predicting transmural scars were $96 \%$ and $88 \%$, respectively, at an STR cut-off value of $40.15 \%$. The area under the curve was 0.925 . Multivariate logistic proportional hazards regression analysis disclosed that patients with STR $<40.15 \%$ had a 170.90 -fold higher probability of developing transmural scars compared with patients with STR $\geq 40.15 \%$. Pearson correlation and linear regression analyses showed STR percentage was significantly associated with myocardial scar thickness and size.
\end{abstract}

Conclusion: STR $<40.15 \%$ at $24 \mathrm{~h}$ after $\mathrm{PCl}$ may provide meaningful diagnostic information regarding the extent of myocardial scarification in STEMI patients.

Keywords: ST-segment resolution, ST-elevation myocardial infarction, Percutaneous coronary intervention, Myocardial scar

\section{Introduction}

Transmural myocardial scars of the left ventricle that complicate ST-segment elevation myocardial infarction (STEMI) predispose to heart failure and cardiac death. Therefore, early identification and analysis of myocardial scars are particularly important [1]. The size and tissue heterogeneity of healing scars identified by late

\footnotetext{
*Correspondence: zhangdongying@cqmu.edu.cn; 1296224271@qq.com ${ }^{1}$ Department of Cardiology, The First Affiliated Hospital of Chongqing Medical University, Yuzhong, Chongqing, China

Full list of author information is available at the end of the article
}

gadolinium-enhanced cardiac magnetic resonance imaging (CMR-LGE) are independent predictors of arrhythmia and sudden cardiac death [2-7]. CMR-LGE is the gold standard for the diagnosis of myocardial scar and assessment of myocardial salvage [8-11], but is expensive, time-consuming, unfit for wide population studies, and generally contraindicated in patients with cardiac implants. These disadvantages have restricted its clinical application.

Delayed ST-segment resolution (STR) is prevalent during major adverse cardiovascular events, and is predictive of arrhythmia, heart failure, and 30-day mortality [12]. 
We hypothesized that analysis of STR could represent a convenient, widely accessible, and inexpensive diagnostic method for patients who cannot tolerate CMR-LGE. Consequently, the aim of our study was to establish whether poor STR, as well as CMR-LGE findings, can detect myocardial scarification in the early post-infarction period in STEMI patients.

\section{Methods}

\section{Study design and population}

Forty-two consecutive patients with STEMI treated with coronary angiography and percutaneous coronary intervention (PCI) within $12 \mathrm{~h}$ of the onset of pain were enrolled between March 2017 and October 2017. Inclusion criteria were (1) single-branch coronary artery stenosis or occlusion, and (2) restoration of coronary perfusion to TIMI flow grade 3 after PCI. Exclusion criteria were a prior history of the acute coronary syndrome; coronary revascularization; severe chronic kidney disease; intracardiac pacing leads or other implants precluding CMR-LGE; hemodynamic instability; or known claustrophobia. The study was performed at the First Affiliated Hospital of Chongqing Medical University, China. Demographic and clinical characteristics including ECG STR $24 \mathrm{~h}$ after PCI were recorded. CMR-LGE was performed 7 days after PCI. This study was conducted in accordance with the Declaration of Helsinki. The research protocol was approved by the locally appointed Ethics Committee, and written informed consent was obtained from all study participants.

\section{CMR-LGE protocols}

Patients were examined in the supine position using a 1.5-T imaging unit (Signa Infinity Twinspeed, General Electric Healthcare, USA) equipped with master gradients $(30 \mathrm{mT} / \mathrm{m}$ peak gradients; $150 \mathrm{mT} / \mathrm{m} / \mathrm{ms}$ slew rate) and a 5-element cardiac phased-array receiver coil. Images were obtained using electrocardiographic gating and expiratory breath holds. A dose of $0.2 \mathrm{mmol} / \mathrm{kg}$ of body weight of gadopentetate dimeglumine (Magnevist; Bayer Schering Health Care, Cambridge, UK) was administered intravenously at a rate of $5 \mathrm{ml} / \mathrm{s}$ with a power injector. Ten minutes after contrast agent injection, a Look-Locker sequence was performed to obtain the most appropriate inversion time to nullify the signal intensity of normal myocardium. The left ventricular short-axis imaging layer was $8 \mathrm{~mm}$ thick and $0 \mathrm{~mm}$ apart. The left ventricular 2-chamber and 4-chamber scanning imaging layers were $5 \mathrm{~mm}$ thick and $0 \mathrm{~mm}$ apart. This was immediately followed by the acquisition of LGE images, with an inversion recovery prepared T1-weighted gradient-echo sequence (4.9/1.9; flip angle, 15 degrees; turbo field-echo factor, 30; spatial resolution, $1.35 \times 1.35 \times 10 \mathrm{~mm}$ ). Late gadolinium enhancement was interpreted as present or absent by the consensus of two CMR-trained physicians, and was considered present only if confirmed on both short-axis and matching long-axis myocardial locations.

First, we marked the segments of the myocardial scar with the bull's eye segmental comparison (17-segment model) and compared them with the results of coronary angiography. Second, we searched for the thickest myocardial scar layer-by-layer on the short axis imaging and calculated the percentage of the thickness of the myocardial scar, which was defined as a transmural myocardial scar when the percentage was $>75 \%$, according to previous study [13]. Beek et al. demonstrated that the transmural extent is relevant in predicting myocardial functional recovery: The likelihood of complete functional recovery of segments without LGE was 3.8, 11.1, and 50 times higher than that of segments with $26-50 \%$, $51-75 \%$, and $>75 \%$ LGE, respectively $(P<0.001)$ [13]. Finally, we recorded the area of myocardial scar and calculated the percentage of myocardial scar volume by segment software.

\section{ECG protocols}

Standard 18-lead ECGs were obtained at emergency admission and $24 \mathrm{~h}$ after coronary angiography and PCI. The TP segment was used as the isoelectric line in the ST-segment measurement. The ST segment was measured $20 \mathrm{~ms}$ after the J point. The summed ST-segment elevation was measured by adding the ST amplitude in all leads with ST-elevation at emergency admission and $24 \mathrm{~h}$ after PCI [14-16]. STR percentage was calculated as the initial sum of ST-segment elevation minus the sum of ST-segment elevation on the second ECG, divided by the initial sum of ST-segment elevation.

\section{Statistical analysis}

Basic descriptive statistics were used. CMR-LGE location data were described on a patient-by-patient basis. Statistical analyses were performed to assess the clinical utility of using of STR to predict myocardial scarification. Myocardial scars were assessed using two measures: (1) scar thickness and (2) scar size. Receiver operating characteristic (ROC) curve analysis, logistic regression analysis, and multivariate logistic proportional-hazards regression estimated transmural myocardial scar. Pearson correlation and linear regression analyses were used to investigate the coefficients of STR percentage with myocardial scar thickness and size. Myocardial scar thickness and size difference between two ST-segment resolution groups were analyzed by $t$-test. All statistical 
analyses were performed using SPSS v.22.0 (IBM, Armonk, NY, USA). $P$ value $<0.05$ was considered statistically significant.

\section{Results}

Location, size, thickness of the myocardial scar determined by CMR-LGE

Myocardial scars were diagnosed in 41 of 42 STEMI patients (96.7\%) by using CMR-LGE. A patient-bypatient visual analysis of scar tissue location in the STEMI group, with bull's eye segmental comparison of CMR-LGE findings is shown in Additional file 1: Fig. S1. In all patients, the anatomic locations of scars defined by CMR-LGE corresponded to the distributions of the culprit vessels treated with primary angioplasty. For example, in a patient with angiographically proven left anterior descending coronary artery occlusion, CMRLGE indicated scarification of the basal and middle segments of the left anterior ventricular wall. In another patient with right coronary artery occlusion, CMR-LGE disclosed a scar that involved the entire inferior wall of the left ventricle and the middle and apical segments of the posterior interventricular septum (Additional file 1: Fig. S2). However, scar size and thickness were unrelated to the degree of coronary artery occlusion. Stenoses in all culprit arteries exceeded 90\%; nonetheless, there were significant inter-patient differences in scar size and thickness $(P<0.001)$.

\section{Determination of STR cut-off value}

A transmural scar was defined as a myocardial lesion extending $>75 \%$ of the wall thickness. All myocardial scars were classified as either non-transmural (0-75\%) or transmural (76-100\%) according to CMR-LGE results. The relationship of the ST-segment resolution percentage to transmural scarification was identified by the ROC curve. The ROC curve analysis demonstrated a sensitivity of $96 \%$ and a specificity of $88 \%$ to predict transmural myocardial scarification following STEMI at an STR cutoff value of $40.15 \%$. The area under the curve was 0.925 (Fig. 1).

The cut-off of ST-segment resolution of $40.15 \%$. Area under curve $(\mathrm{AUC})=0.925$.

\section{Patient characteristics of STR groups}

Patients were divided into two groups: STR $<40.15 \%$ $(\mathrm{n}=16)$ and STR $\geq 40.15 \% \quad(\mathrm{n}=26)$. Compared with patients with STR $\geq 40.15 \%$, patients with STR $<40.15 \%$ had significantly longer pain-to-balloon time; higher aspartate aminotransferase (AST), peak troponin-I, and brain natriuretic peptide (BNP) levels; lower left ventricular ejection fraction (LVEF); and a higher prevalence of

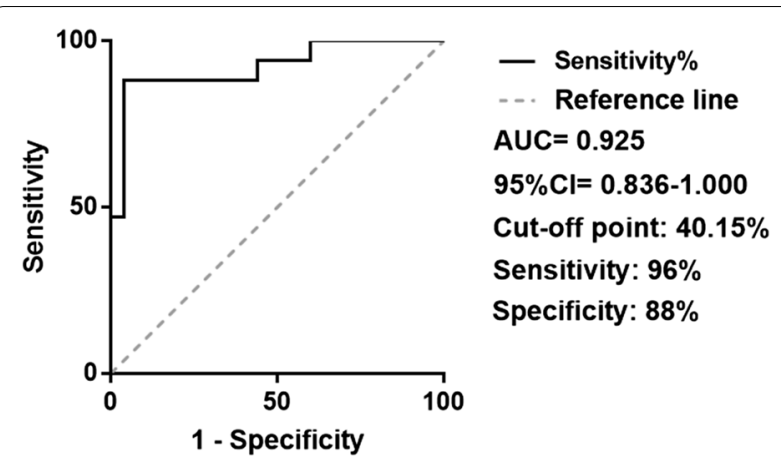

Fig. 1 ST-segment resolution with transmural myocardial scar. ROC curve analysis demonstrated the sensitivity and specificity of ST-segment resolution for predicting transmural cardiac scarring after STEMI were $96 \%$ and $88 \%$

diuretic therapy. Other characteristics such as age; gender; body mass index; histories of smoking, hypertension, and diabetes; hyperlipidemia; culprit artery; leukocyte, erythrocyte, and platelet counts; hemoglobin, hemoglobin A1(c), alanine aminotransferase (ALT), and creatinine levels; left ventricular diastolic diameter; the use of therapeutic drugs other than diuretics; and coronary care unit residence time were similar between the two groups (Table 1).

\section{Diagnostic value of STR $<40.15 \%$ for transmural myocardial scar}

In the logistic regression analysis, $\mathrm{LVEF}(\mathrm{OR}=0.520,95 \%$ CI $0.341-0.792)$, and STR $<40.15 \%(\mathrm{OR}=15.0,95 \% \mathrm{CI}$ 1.981-113.556) were significant risk factors for transmural scars (Table 2).

Multivariate logistic proportional hazards regression analyses were used to evaluate the independent predictive value of STR $<40.15 \%$. After adjusting for BNP, Peak Troponin-I, AST, the OR of STR $<40.15 \%$ for transmural scar was 170.90 (95\% CI 2.26-12,953.74, $P=0.020)$. STR $<40.15 \%$ showed significance for predicting transmural scar (Table 3).

\section{Relationship between STR percentage and myocardial scar thickness and size}

Pearson correlation analysis demonstrated negative correlations between STR percentage and both scar thickness $(\mathrm{r}=-0.838, P<0.001)$ and size $(\mathrm{r}=-0.714$, $P<0.001$ ) (Fig. 2). Linear regression analysis with STR (\%) as the independent variable and myocardial scar thickness and size as dependent variables were performed. For every $1 \%$ decrease in STR, the myocardial scar thickness and size decreases by $0.718 \%$ ( $95 \%$ CI $-0.867 \sim-0.568$, 
Table 1 Baseline patient characteristics of different degrees of ST-segment resolution

\begin{tabular}{|c|c|c|c|c|}
\hline Variables & All $(n=42)$ & $\begin{array}{l}\text { ST-segment } \\
\text { resolution } \geq 40.15 \% \\
(n=26)\end{array}$ & $\begin{array}{l}\text { ST-segment } \\
\text { resolution }<40.15 \% \\
(n=16)\end{array}$ & $P$ \\
\hline Male/female (n) & $30 / 12$ & $20 / 6$ & $10 / 6$ & 0.483 \\
\hline Age (years) & $62.0(54.5-70.0)$ & $60.5(52.8-70.3)$ & $63.5(59.5-69.5)$ & 0.534 \\
\hline $\mathrm{BMI}\left(\mathrm{Kg} / \mathrm{m}^{2}\right)$ & $24.2(23.0-25.6)$ & $24.3(23.4-25.8)$ & $24.2(21.9-24.7)$ & 0.378 \\
\hline Smoking history (No, \%) & $27(64.3 \%)$ & $17(65.4 \%)$ & $10(62.5 \%)$ & 0.850 \\
\hline HP history (no, \%) & $27(64.3 \%)$ & $14(53.8 \%)$ & $13(81.2 \%)$ & 0.072 \\
\hline DM history (no, \%) & $16(38.1 \%)$ & $12(46.2 \%)$ & $4(25.0 \%)$ & 0.170 \\
\hline Hyperlipidemia (no, \%) & $21(50.0 \%)$ & $13(50.0 \%)$ & $8(8.0 \%)$ & 1.000 \\
\hline Pain to balloon time (h) & $5.79(3.67-7.60)$ & $4.33(3.50-6.23)$ & $7.04(5.81-8.40) *$ & 0.001 \\
\hline Killip classification (no, \%) & & & & 0.757 \\
\hline Killip I & $29(74.4 \%)$ & $19(79.2 \%)$ & $10(66.67 \%)$ & \\
\hline Killip II & $10(25.6 \%)$ & $5(20.8 \%)$ & $5(33.33 \%)$ & \\
\hline Number of DES (no, \%) & & & & 0.142 \\
\hline One & $34(87.2 \%)$ & $22(95.7 \%)$ & $12(75.0 \%)$ & \\
\hline Two & $3(7.7 \%)$ & $1(4.3 \%)$ & $2(12.5 \%)$ & \\
\hline Three & $2(5.1 \%)$ & $0(0.0 \%)$ & $2(12.5 \%)$ & \\
\hline Culprit artery, (No, \%) & & & & 0.171 \\
\hline LAD & $18(42.9 \%)$ & $8(30.8 \%)$ & $10(62.5 \%)$ & \\
\hline LCC & $11(26.2 \%)$ & $8(30.8 \%)$ & $3(18.8 \%)$ & \\
\hline RCA & $13(31.0 \%)$ & $10(38.5 \%)$ & $3(18.8 \%)$ & \\
\hline WBC count $\left(10^{9} / \mathrm{L}\right)$ & $9.85(8.28-12.06)$ & $10.09(8.28-12.06)$ & $9.72(8.03-14.12)$ & 0.875 \\
\hline RBC count $\left(10^{12} / \mathrm{L}\right)$ & $4.44(3.91-4.82)$ & $4.44(4.14-4.86)$ & $4.45(3.71-4.72)$ & 0.449 \\
\hline $\mathrm{Hb}(\mathrm{g} / \mathrm{L})$ & $139.0(125.0-151.0)$ & $139.0(128.0-151.0)$ & $135.5(113.3-150.8)$ & 0.449 \\
\hline $\operatorname{PLT}\left(10^{9} / \mathrm{L}\right)$ & $198.0(163.0-238.0)$ & $195.0(160.0-213.0)$ & $212.5(175.0-282.3)$ & 0.204 \\
\hline HbA1c (\%) & $6.0(5.7-7.2)$ & $6.1(5.7-8.2)$ & $5.9(5.7-6.4)$ & 0.188 \\
\hline ALT (U/L) & $42.0(35.0-56.0)$ & $41.0(35.0-56.0)$ & $46.0(36.0-53.5)$ & 0.689 \\
\hline AST $(U / L)$ & $126.0(52.0-209.0)$ & $75.0(35.0-153.0)$ & $185.5(101.1-237.3)$ & 0.015 \\
\hline $\mathrm{Cr}(\mathrm{umol} / \mathrm{L})$ & $73.0(60.0-81.0)$ & $73.0(59.0-81.0)$ & $71.5(60.3-83.3)$ & 0.954 \\
\hline BNP $(p g / m l)$ & $57.9(7.9-245.0)$ & $11.7(5.0-62.7)$ & $227.5(80.0-381.2)^{*}$ & $<0.001$ \\
\hline Peak troponin-T (ng/ml) & $11.6(6.2-19.3)$ & $7.0(3.8-14.0)$ & $18.6(12.2-24.9) *$ & $<0.001$ \\
\hline LVIDd (mm) & $49.0 \pm 3.3$ & $49.0 \pm 3.3$ & $49.5 \pm 3.2$ & 0.298 \\
\hline LVEF (\%) & $53.5(48.0-58.25)$ & $57.0(53.5-61.0)$ & $47.5(44.3-50.0) *$ & $<0.001$ \\
\hline Scar thickness & $70.0(55.0-80.0)$ & $59.0(50.0-70.0)$ & $81.0(80.0-85.0) *$ & $<0.001$ \\
\hline Transmural myocardial scar (no, \%) & $17(40.5 \%)$ & $2(7.7 \%)$ & $15(93.8 \%)^{*}$ & $<0.001$ \\
\hline Scar size & $17.35(12.23-20.30)$ & $12.90(11.13-19.40)$ & $20.00(18.13-23.63)^{*}$ & 0.001 \\
\hline Ila/lllb inhibitor (no, \%) & $17(43.6 \%)$ & $11(47.8 \%)$ & $6(37.5 \%)$ & 0.522 \\
\hline Aspirin (no, \%) & $39(100.0 \%)$ & $23(100.0 \%)$ & $16(100.0 \%)$ & 1.000 \\
\hline Ticagrelor/clopidogrel (no, \%) & $39(100.0 \%)$ & $23(100.0 \%)$ & $16(100.0 \%)$ & 1.000 \\
\hline Statins (no, \%) & $39(100.0 \%)$ & $23(100.0 \%)$ & $16(100.0 \%)$ & 1.000 \\
\hline$\beta$-blocker (no, \%) & $31(79.5 \%)$ & $17(73.9 \%)$ & $14(87.5 \%)$ & 0.432 \\
\hline ACEI/ARB & $24(61.5 \%)$ & $14(60.9 \%)$ & $10(62.5 \%)$ & 0.918 \\
\hline Nitrates (no, \%) & $38(97.4 \%)$ & $22(95.7 \%)$ & $16(100.0 \%)$ & 1.000 \\
\hline Diuretics (no, \%) & $16(41.0 \%)$ & $6(26.1 \%)$ & $10(62.5 \%)$ & 0.023 \\
\hline CCU (hours) & $48.0(39.0-62.0)$ & $47.0(38.0-58.0)$ & $52.5(44.0-82.8)$ & 0.123 \\
\hline
\end{tabular}

Data are data are presented as mean \pm SD, median (interquartile ranges), or number (\%)

STEMI ST-segment elevation myocardial infarction, $B M I$ body mass index, HP hypertension, DM diabetes mellitus, DES drug eluting stents, $L A D$ left anterior descending coronary artery, $L C C$ left circumflex coronary artery, RCA right coronary artery, LVIDD left ventricular diastolic diameter, $L V E F$ left ventricular ejection fraction, $A C E I$ angiotensin converting enzyme inhibitors, $A R B$ angiotensin receptor blocker, $C C U$ coronary heart disease care unit

${ }^{*} P<0.05$ comparing with ST-segment resolution $\geq 40 \%$ group 
Table 2 Effects of various variables on transmural myocardial scar in logistic regression analysis

\begin{tabular}{|c|c|c|}
\hline Characteristics & OR $(95 \% \mathrm{Cl})$ & $P$ \\
\hline Male, yes versus no & $0.500(0.234-1.068)$ & 0.074 \\
\hline Age, per 1 years & $0.994(0.984-1.004)$ & 0.238 \\
\hline BMl, per $1 \mathrm{~kg} / \mathrm{m}^{2}$ & $0.984(0.959-1.009)$ & 0.206 \\
\hline Smoking history, yes versus no & $0.588(0.269-1.285)$ & 0.183 \\
\hline HP history, yes versus no & $1.077(0.506-2.291)$ & 0.847 \\
\hline DM history, yes versus no & $0.333(0.108-1.034)$ & 0.057 \\
\hline Hyperlipidemia, yes versus no & $0.615(0.255-1.485)$ & 0.280 \\
\hline Pain to balloon time, per 1 min & $1.018(0.928-1.118)$ & 0.702 \\
\hline Killip classification, II versus I & $1.500(0.423-5.315)$ & 0.530 \\
\hline Number of DES, two \& three versus one & $4.000(0.447-35.788)$ & 0.215 \\
\hline Culprit artery: RCD & 1.00 & \\
\hline Culprit artery: LAD & $0.571(0.167-1.952)$ & 0.372 \\
\hline Culprit artery: LCC & $0.444(0.137-1.443)$ & 0.177 \\
\hline WBC count, per $1 \times 10^{9} / \mathrm{L}$ & $0.971(0.917-1.028)$ & 0.317 \\
\hline RBC count, per $1 \times 10^{12} / \mathrm{L}$ & $0.915(0.792-1.058)$ & 0.229 \\
\hline $\mathrm{Hb}$, per $1 \times \mathrm{g} / \mathrm{L}$ & $0.997(0.993-1.002)$ & 0.241 \\
\hline PLT, per $1 \times 10^{9} / \mathrm{L}$ & $0.999(0.996-1.002)$ & 0.567 \\
\hline HbA1c, per $1 \%$ & $0.936(0.852-1.029)$ & 0.172 \\
\hline ALT, per $1 \mathrm{U} / \mathrm{L}$ & $0.995(0.984-1.007)$ & 0.442 \\
\hline AST, per $1 \mathrm{U} / \mathrm{L}$ & $1.001(0.998-1.004)$ & 0.561 \\
\hline $\mathrm{Cr}$, per $1 \mathrm{umol} / \mathrm{L}$ & $0.995(0.987-1.004)$ & 0.283 \\
\hline BNP, per $1 \mathrm{pg} / \mathrm{ml}$ & $1.003(0.999-1.008)$ & 0.120 \\
\hline Peak troponin-T, per 1 ng/ml & $1.014(0.975-1.054)$ & 0.500 \\
\hline LVIDd, per $1 \mathrm{~mm}$ & $0.993(0.980-1.005)$ & 0.255 \\
\hline LVEF, per $1 \%$ & $0.520(0.341-0.792)$ & 0.002 \\
\hline ST-segment $<40.15 \%$, yes versus no & $15.0(1.981-113.556)$ & 0.009 \\
\hline Scar thickness & $1.000(0.991-1.009)$ & 0.975 \\
\hline Scar size & $0.993(0.960-1.027)$ & 0.685 \\
\hline Ila/lllb inhibitor, yes versus no & $0.545(0.202-1.475)$ & 0.232 \\
\hline$\beta$-blocker, yes versus no & $0.824(0.406-1.671)$ & 0.591 \\
\hline ACEI/ARB, yes versus no & $0.846(0.379-1.889)$ & 0.683 \\
\hline Nitrates, yes versus no & $0.727(0.382-1.385)$ & 0.332 \\
\hline Diuretics, yes versus no & $2.200(0.764-6.332)$ & 0.144 \\
\hline$C C U$, per $1 \mathrm{~h}$ & $1.000(0.989-1.011)$ & 0.987 \\
\hline
\end{tabular}

STEMI ST-segment elevation myocardial infarction, $B M I$ body mass index, $H P$ hypertension, $D M$ diabetes mellitus, DES drug eluting stents, $L A D$ left anterior descending coronary artery, $L C C$ left circumflex coronary artery, $R C A$ right coronary artery, WBC white blood cell, $R B C$ red blood cell, $\mathrm{Hb}$ haemoglobin, PLT platelet count, $H b A 1 c$ hemoglobin A1c, ALT alanine aminotransferase, AST aspartate transaminase, $C r$ creatinine, BNP brain natriuretic peptide, $L V I D D$ left ventricular diastolic diameter, $L V E F$ left ventricular ejection fraction, $A C E I$ angiotensin converting enzyme inhibitors, $A R B$ angiotensin receptor blocker, CCU coronary heart disease care unit

$P<0.001)$ and $0.214 \% \quad(95 \% \quad \mathrm{CI} \quad-0.281 \sim-0.147$, $P<0.001$ ), respectively (Table 4 ). In addition, compared with patients with STR $>40.15 \%$, patients with STR $<40.15 \%$ had significantly thicker and larger scars (Fig. 3).
Table 3 Results of multivariate logistic proportional-hazards regression analyzing the effect of baseline variables on transmural myocardial scar

\begin{tabular}{lcc}
\hline Model & OR (95\%Cl) & $P$ \\
\hline $\begin{array}{l}\text { Not adjusted ST-segment resolu- } \\
\text { tion<40.15\%, yes versus no }\end{array}$ & $15.0(1.98-113.56)$ & 0.009 \\
$\begin{array}{l}\text { Model } \\
\text { ST-segment resolution <40.15\%, }\end{array}$ & $170.90(2.26-12,953.74)$ & \\
$\quad$ yes versus no & 0.020 \\
BNP, per 1 pg/ml & $1.01(0.99-1.02)$ & 0.313 \\
Peak troponin-I, per 1 ng/ml & $0.95(0.75-1.21)$ & 0.695 \\
AST, per 1U/L & $1.00(0.99-1.02)$ & 0.615 \\
\hline
\end{tabular}

STEMI ST-segment elevation myocardial infarction, BNP brain natriuretic peptide, LVEF left ventricular ejection fraction, $A S T$ aspartate transaminase

\section{Discussion}

Our study showed that ECG, as a convenient and noninvasive technique, can monitor the occurrence of transmural myocardial fibrosis after acute myocardial infarction. In our study, it is possible to detect myocardial scar by CMR-LGE at 7 days after PCI, even when PCI is performed within $12 \mathrm{~h}$ of the onset of pain. Many previous studies have focused on the correlation between STR in ECG and poor prognosis in patients with MI, but no cutoff value and clinical markers have been formed. Our study attempted to quantify the predictive value of STR for transmural myocardial scar after STEMI using a small sample.In our study population, there were no statistically significant differences in gender, age, BMI, smoking history, hypertension history, diabetes history, hyperlipidemia history, culprit artery, number of stent implantation, hemogram, HbA1c, ALT, CCU time and the use of drugs including IIa/IIIb inhibitor, Aspirin, Ticagrelor/ Clopidogrel, Statins, $\beta$-blocker, ACEI/ARB, Nitrates, Diuretics. However, compared with the STR $\geq 40.15 \%$ group, the incidence of transmural myocardial fibrosis was higher $(P<0.001)$ and the size of myocardial scar was larger $(P=0.001)$ in the STR $<40.15 \%$ group, the difference was statistically significant (Table 1 ).

Although many researchers believe the association of ST segment resolution and transmural myocardial scar, no one has really verified and quantified it. The association between them may help diagnose myocardial fibrosis simply and quickly in the early clinical stage. Therefore, we use actual cases to verify and quantify the connection between ST segment resolution and transmural myocardial scar. It is significant to quantify STR and apply such a convenient and non-invasive technique to the clinical monitoring of transmural fibrosis in myocardial infarction. Although CMR-LGE is the gold standard for the diagnosis of myocardial fibrosis, patients with cardiac scar often cannot tolerate CMR-LGE and other methods 

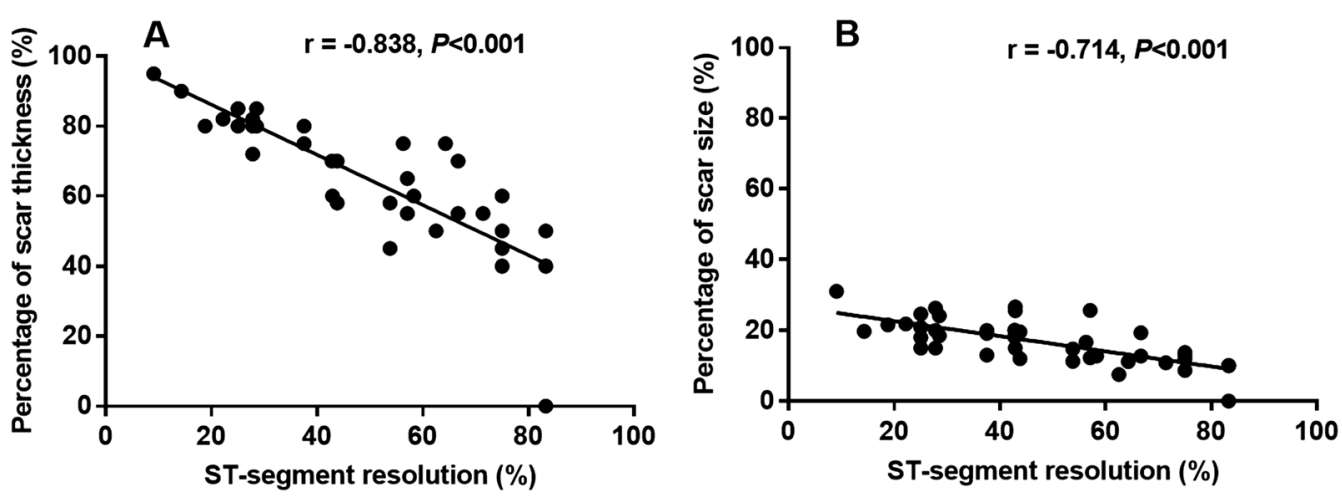

Fig. 2 Pearson correlation analysis between ST-segment resolution and myocardial scar thickness or size. A Pearson correlation analysis was performed to evaluate ST-segment resolution was negatively correlated with scar thickness. $r=-0.838, P<0.001$. B Pearson correlation analysis was performed to evaluate ST-segment resolution was negatively correlated with scar size. $r=-0.714, P<0.001$

Table 4 Results of linear regression analysis with ST-segment resolution (\%) as the independent variable and myocardial scar thickness and size as dependent variables

\begin{tabular}{lllllll}
\hline Dependent variables & R2 & B & Std.error & t & P & 95\% Cl for B \\
\hline Myocardial scar thickness & 0.702 & -0.718 & 0.074 & -9.707 & $<0.001$ & $(-0.867,-0.568)$ \\
Myocardial scar size & 0.510 & -0.214 & 0.033 & -6.453 & $<0.001$ & $(-0.281,-0.147)$ \\
\hline
\end{tabular}
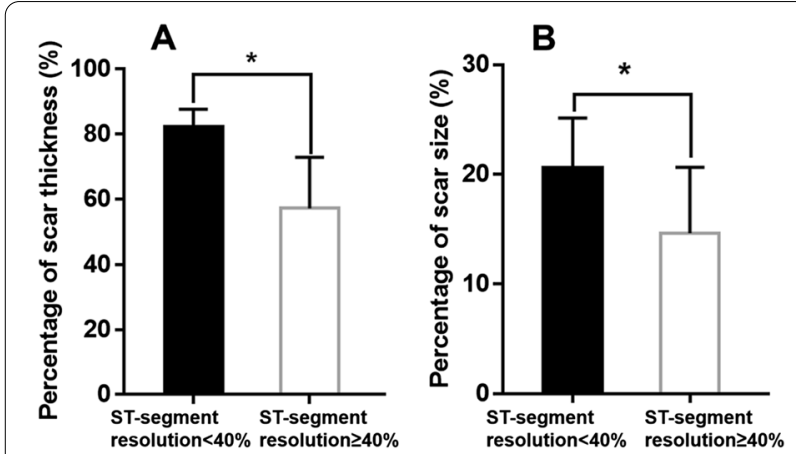

Fig. 3 Myocardial scar thickness and size difference between two ST-segment resolution groups. A Myocardial scar thickness was statistically significant in patients with ST-segment resolution $<40.15 \%$ and in patients with ST-segment resolution $\geq 40.15 \%$ (t-Test). Data are reported as mean $\pm S D$. ${ }^{*} P<0.001$. B Myocardial scar size was statistically significant in patients with ST-segment resolution $<40.15 \%$ and in patients with ST-segment resolution $\geq 40.15 \%$ (t-Test). Data are reported as mean \pm SD. ${ }^{*} P<0.001$

are needed to diagnose transmural scar. STR is a useful predictor of the final infarct size, left ventricular function, and clinical outcome after early reperfusion [17-19]. Nonetheless, the predictive value of STR is still controversial [20, 21]. Rakowski et al. showed that STR $<70 \%$ is a marker of large infarct size [21]. However, the transmural depth of an infarction is more consequential than its size. To the best of our knowledge, there are no data to date on the relationship between STR and the transmural thickness of infarcted myocardium. Therefore, our study was focused on defining a specific cut-off value of STR for the diagnosis of transmural scars. We found that the predicted critical value of STR of a transmural myocardial scar after STEMI was $40.15 \%$, with a sensitivity of $96 \%$ and a specificity of $88 \%$ (Fig. 1). Poor STR was related to thicker and larger scars (Figs. 2, 3). Previous studies have reported relationships between STR and reduced myocardial perfusion and between early STR and myocardial rescue [22]. In addition, STR following PCI and restoration of perfusion to TIMI flow grade 3 was correlated with collateral circulation [23]. STR $<50 \%$ may be associated with worse left ventricular function and increased mortality $[11,24]$. These results are consistent with our findings, but our study found that patients with STR $>40.15 \%$ had thinner and smaller myocardial scar.

STR is significant in monitoring the prognosis and treatment of transmural myocardial fibrosis after myocardial infarction. Transmural myocardial scars are caused by ischemic injury followed by fibrosis of necrotic tissue [1, 25-27]. Poor perfusion, limited myocardial salvage, and microvascular disease promote scarification. The severity and localization of ventricular wall injuries are also influenced by the length of coronary artery stenosis and the degree of collateral circulation [28-30]. The extent of myocardial fibrosis is an important determinant 
of prognosis. In STEMI, transmural MF usually leads to irreversible ventricular remodeling and heart failure, and is also the pathological basis for arrhythmias, and is generally considered to be associated with sudden cardiac death [31-34]. Nguyen et al. [35] found that the severity of myocardial fibrosis was significantly correlated with the frequency of ventricular arrhythmias $(r=0.83$, $P<0.01$ ). Our study showed that the STR $<40.15 \%$ group had a higher incidence of transmural myocardial fibrosis, and no differences in the incidence of arrhythmias and readmission rate were found between the two groups, which may be related to the small sample size (Additional file 1: Fig. S3). Scientists' understanding of the mechanisms and consequences of cardiac fibrosis has only improved greatly in recent years, with the improvement of non-invasive techniques to better track its development [36]. It is significant to explore the effect of STR on the prognosis of transmural myocardial fibrosis after myocardial infarction in a larger sample and a longer follow-up time.

The physiology of STR is related to the restoration of myocardial perfusion. Following PCI of epicardial coronary arteries, microvascular spasm and embolism may lead to persistent coronary microvascular dysfunction (CMD) and subsequently cause myocardial and especially endocardial ischemia. In the setting of CMD, extracellular potassium ion clearance is decreased, thus prolonging repolarization and delaying STR. Poor STR reflects microvascular and left ventricular dysfunction [20, 37, 38], and is thereby an important biomarker of CMD after PCI in STEMI patients. Inadequate perfusion due to CMD is the proximate cause of transmural myocardial injury; consequently, assessment of the severity of ischemia by monitoring dynamic ST-segment changes is of the utmost importance. In our study, it was found that compared with the group with STR $\geq 40.15 \%$, the pain to balloon time was significantly prolonged $(P=0.001)$, the left ventricular ejection fraction was significantly reduced $(P<0.001)$, and the troponin and BNP were higher $(P<0.001)$ in the group with STR $<40.15 \%$. The delay of opening time of effective coronary blood flow in STR $<40.15 \%$ group may be an important reason for the aggravation of myocardial transmural injury and the formation of transmural myocardial fibrosis. Shortening the pain to balloon time may avoid or reduce the occurrence of poor STR, thus affecting the clinical prognosis of patients.

\section{Limitations}

There are several limitations of this study. First, this was a cross-sectional study with a relatively small number of patients. Second, it was difficult to recruit STEMI patients who were willing or able to undergo CMR-LGE
7 days after PCI. Third, because this study was limited to STEMI patients, cross-validation analysis is needed to determine whether delayed STR can be used to predict myocardial scarification in non-STEMI patients. Fourth, to verify the clinical effects of STR, longer clinical followup is needed, especially for the monitoring and follow-up of malignant arrhythmias.

\section{Conclusion}

We found that STR correlated with myocardial scar thickness following STEMI. To the best of our knowledge, this is the first study to confirm that STR $<40.15 \%$ after PCI can provide important prognostic information regarding myocardial fibrosis in STEMI patients. These results suggest that STR may represent a safe, readily accessible, easily administered, inexpensive diagnostic modality in the management of STEMI patients for whom CMR-LGE is contraindicated.

\section{Supplementary Information}

The online version contains supplementary material available at https://doi. org/10.1186/s12872-021-02269-y.

Additional file 1. Eye representation of segments in which visual analysis of CMR-LGE detected scar tissue.

\section{Acknowledgements}

We thank Linbo Chen for his contribution during various stages of the paper preparation.

\section{Authors' contributions}

SQ provided ideas and plans for the entire research. QD and DZ wrote the main manuscript text. RX and SW prepared Additional file 1: Figs. S1 and S2. YY and GC prepared Figs. 1, 2 and 3. XW prepared Tables 1, 2, 3 and Additional file 1: Fig. S3. YT provided statistical support for the overall data. All authors read and approved the final manuscript.

\section{Funding}

The study was supported by The First Affiliated Hospital of Chongqing Medical University Cultivation Fund (No. PYJJ 2017-35).

\section{Availability of data and materials}

The datasets used and analyzed during the current study are available from the corresponding author on reasonable request.

\section{Declarations}

Ethics approval and consent to participate

This study was registered in clinicaltrials.gov (Approval No. NCT04586582). The study was conducted in accordance with the "Declaration of Helsinki" and approved by the ethics committee of the first affiliated hospital of Chongqing medical university (Approval No. 2019-057). We followed ethical guidelines and obtained informed consent from the participants.

\section{Consent for publication}

Not applicable.

\section{Competing interests}

The authors declare that they have no conflicts of interest. The authors are accountable for all aspects of the work in ensuring that questions related to 
the accuracy or integrity of any part of the work are appropriately investigated and resolved.

\section{Author details}

${ }^{1}$ Department of Cardiology, The First Affiliated Hospital of Chongqing Medical University, Yuzhong, Chongqing, China. ${ }^{2}$ Chongqing Medical University, Yuzhong, Chongqing, China. ${ }^{3}$ Department of Radiology, The First Affiliated Hospital of Chongqing Medical University, Yuzhong, Chongqing, China.

Received: 26 May 2021 Accepted: 14 September 2021

Published online: 21 September 2021

\section{References}

1. Stone GW, Selker HP, Thiele H, Patel MR, Udelson JE, Ohman EM, et al. Relationship between infarct size and outcomes following primary PCl: patient-level analysis from 10 randomized trials. J Am Coll Cardiol. 2016;67(14):1674-83.

2. Schmidt A, Azevedo CF, Cheng A, Gupta SN, Bluemke DA, Foo TK, et al. Infarct tissue heterogeneity by magnetic resonance imaging identifies enhanced cardiac arrhythmia susceptibility in patients with left ventricular dysfunction. Circulation. 2007;115(15):2006-14.

3. Iles L, Pfluger H, Lefkovits L, Butler MJ, Kistler PM, Kaye DM, et al. Myocardial fibrosis predicts appropriate device therapy in patients with implantable cardioverter-defibrillators for primary prevention of sudden cardiac death. J Am Coll Cardiol. 2011;57(7):821-8.

4. Klem I, Weinsaft JW, Bahnson TD, Hegland D, Kim HW, Hayes B, et al. Assessment of myocardial scarring improves risk stratification in patients evaluated for cardiac defibrillator implantation. J Am Coll Cardiol. 2012:60(5):408-20.

5. Bello D, Fieno DS, Kim RJ, Pereles FS, Passman R, Song G, et al. Infarct morphology identifies patients with substrate for sustained ventricular tachycardia. J Am Coll Cardiol. 2005;45(7):1104-8.

6. Izquierdo M, Ruiz-Granell R, Bonanad C, Chaustre F, Gomez C, Ferrero A et al. Value of early cardiovascular magnetic resonance for the prediction of adverse arrhythmic cardiac events after a first noncomplicated ST-segment-elevation myocardial infarction. Circ Cardiovasc Imaging. 2013:6(5):755-61.

7. Fernandez-Armenta J, Berruezo A, Mont L, Sitges M, Andreu D, Silva E, et al. Use of myocardial scar characterization to predict ventricular arrhythmia in cardiac resynchronization therapy. Eur Eur Pacing Arrhythm Card Electrophysiol J Work Groups Card Pacing Arrhythm Card Cell Electrophysiol Eur Soc Cardiol. 2012;14(11):1578-86.

8. Wagner A, Mahrholdt H, Holly TA, Elliott MD, Regenfus M, Parker M, et al. Contrast-enhanced MRI and routine single photon emission computed tomography (SPECT) perfusion imaging for detection of subendocardial myocardial infarcts: an imaging study. Lancet. 2003;361(9355):374-9.

9. Bulluck H, Dharmakumar R, Arai AE, Berry C, Hausenloy DJ. Cardiovascular magnetic resonance in acute ST-segment-elevation myocardial infarction: recent advances, controversies, and future directions. Circulation. 2018;137(18):1949-64

10. Schulz-Menger J, Bluemke DA, Bremerich J, Flamm SD, Fogel MA, Friedrich $M G$, et al. Standardized image interpretation and post-processing in cardiovascular magnetic resonance-2020 update: society for cardiovascular magnetic resonance (SCMR): board of trustees task force on standardized post-processing. J Cardiovasc Magn Reson. 2020:22(1):19.

11. Botker HE, Kaltoft AK, Pedersen SF, Kim WY. Measuring myocardial salvage. Cardiovasc Res. 2012;94(2):266-75.

12. de Lemos JA, Antman EM, Giugliano RP, Morrow DA, McCabe CH, Cutler SS, et al. Comparison of a 60 - versus 90 -minute determination of ST-segment resolution after thrombolytic therapy for acute myocardial infarction. In TIME-II Investigators. Intravenous nPA for treatment of infarcting myocardium early-II. Am J Cardiol. 2000;86(11):1235-1127.

13. Beek AM, Kuhl HP, Bondarenko O, Twisk JW, Hofman MB, van Dockum WG, et al. Delayed contrast-enhanced magnetic resonance imaging for the prediction of regional functional improvement after acute myocardial infarction. J Am Coll Cardiol. 2003:42(5):895-901.

14. Schroder R, Wegscheider K, Schroder K, Dissmann R, Meyer-Sabellek W. Extent of early ST segment elevation resolution: a strong predictor of outcome in patients with acute myocardial infarction and a sensitive measure to compare thrombolytic regimens. A substudy of the international joint efficacy comparison of thrombolytics (INJECT) trial. J Am Coll Cardiol. 1995;26(7):1657-64

15. Gragnano F, Spedicato V, Frigoli E, Gargiulo G, Di Maio D, Fimiani F, et al. ECG analysis in patients with acute coronary syndrome undergoing invasive management: rationale and design of the electrocardiography sub-study of the MATRIX trial. J Electrocardiol. 2019;57:44-54.

16. Calabrò P, Gragnano F, Di Maio M, Patti G, Antonucci E, Cirillo P, et al. Epidemiology and management of patients with acute coronary syndromes in contemporary real-world practice: evolving trends from the EYESHOT study to the START-ANTIPLATELET registry. Angiology. 2018;69(9):795-802.

17. de Lemos JA, Braunwald E. ST segment resolution as a tool for assessing the efficacy of reperfusion therapy. J Am Coll Cardiol. 2001:38(5):1283-94.

18. Angeja BG, Gunda M, Murphy SA, Sobel BE, Rundle AC, Syed M, et al. TIMI myocardial perfusion grade and ST segment resolution: association with infarct size as assessed by single photon emission computed tomography imaging. Circulation. 2002;105(3):282-5.

19. Bendary A, Tawfeek W, Mahros M, Salem M. Impact of ST-segment resolution on clinical outcome in patients with ST-segment elevation myocardial infarction and preserved left ventricular function. Ann Noninvasive Electrocardiol. 2018;23(5):e12562.

20. Carrick D, Haig C, Carberry J, May VTY, McCartney P, Welsh P, et al. Microvascular resistance of the culprit coronary artery in acute ST-elevation myocardial infarction. JCI Insight. 2016;1(6):e85768.

21. Rakowski T, Dziewierz A, Siudak Z, Mielecki W, Brzozowska-Czarnek A, Legutko J, et al. ST-segment resolution assessed immediately after primary percutaneous coronary intervention correlates with infarct size and left ventricular function in cardiac magnetic resonance at 1-year follow-up. J Electrocardiol. 2009;42(2):152-6.

22. Dong J, Ndrepepa G, Schmitt C, Mehilli J, Schmieder S, Schwaiger M, et al. Early resolution of ST-segment elevation correlates with myocardial salvage assessed by Tc-99m sestamibi scintigraphy in patients with acute myocardial infarction after mechanical or thrombolytic reperfusion therapy. Circulation. 2002:105(25):2946-9.

23. Sezer M, Nisanci Y, Umman B, Yilmaz E, Olcay A, Erzengin F, et al. New support for clarifying the relation between ST segment resolution and microvascular function: degree of ST segment resolution correlates with the pressure derived collateral flow index. Heart. 2004;90(2):146-50.

24. Purcell IF, Newall N, Farrer M. Change in ST segment elevation 60 minutes after thrombolytic initiation predicts clinical outcome as accurately as later electrocardiographic changes. Heart. 1997;78(5):465-71.

25. Roes SD, Kelle S, Kaandorp TA, Kokocinski T, Poldermans D, Lamb HJ, et al. Comparison of myocardial infarct size assessed with contrast-enhanced magnetic resonance imaging and left ventricular function and volumes to predict mortality in patients with healed myocardial infarction. Am J Cardiol. 2007;100(6):930-6.

26. Cheong BY, Muthupillai R, Wilson JM, Sung A, Huber S, Amin S, et al. Prognostic significance of delayed-enhancement magnetic resonance imaging: survival of 857 patients with and without left ventricular dysfunction. Circulation. 2009;120(21):2069-76.

27. Daniels A, van Bilsen M, Goldschmeding R, van der Vusse GJ, van Nieuwenhoven FA. Connective tissue growth factor and cardiac fibrosis. Acta Physiol (Oxf). 2009;195(3):321-38.

28. Choi JH, Chang SA, Choi JO, Song YB, Hahn JY, Choi SH, et al. Frequency of myocardial infarction and its relationship to angiographic collateral flow in territories supplied by chronically occluded coronary arteries. Circulation. 2013;127(6):703-9.

29. Greulich S, Mayr A, Gloekler S, Seitz A, Birkmeier S, Schaufele T, et al. Timedependent myocardial necrosis in patients with ST-segment-elevation myocardial infarction without angiographic collateral flow visualized by cardiac magnetic resonance imaging: results from the multicenter STEMISCAR project. J Am Heart Assoc. 2019;8(12):e012429.

30. Hoole SP, White PA, Read PA, Heck PM, West NE, O'Sullivan M, et al. Coronary collaterals provide a constant scaffold effect on the left ventricle and limit ischemic left ventricular dysfunction in humans. J Appl Physiol. 2012;112(8):1403-9.

31. Chery G, Kamp N, Kosinski AS, Schmidler GS, Lopes RD, Patel M, et al. Prognostic value of myocardial fibrosis on cardiac magnetic resonance imaging in patients with ischemic cardiomyopathy: a systematic review. Am Heart J. 2020:229:52-60. 
32. Cojan-Minzat BO, Zlibut A, Muresan ID, Cionca C, Horvat D, Kiss E, et al. Left ventricular geometry and replacement fibrosis detected by CMRI are associated with major adverse cardiovascular events in nonischemic dilated cardiomyopathy. J Clin Med. 2020;9(6):1997.

33. von Lueder TG, Wang BH, Kompa AR, Huang L, Webb R, Jordaan P, et al. Angiotensin receptor neprilysin inhibitor LCZ696 attenuates cardiac remodeling and dysfunction after myocardial infarction by reducing cardiac fibrosis and hypertrophy. Circ Heart Fail. 2015;8(1):71-8.

34. Chen Y, Yang S, Yao W, Zhu H, Xu X, Meng G, et al. Prostacyclin analogue beraprost inhibits cardiac fibroblast proliferation depending on prostacyclin receptor activation through a TGF beta-Smad signal pathway. PLoS ONE. 2014;9(5):e98483.

35. Nguyen MN, Kiriazis H, Ruggiero D, Gao XM, Su Y, Jian A, et al. Spontaneous ventricular tachyarrhythmias in beta2-adrenoceptor transgenic mice in relation to cardiac interstitial fibrosis. Am J Physiol Heart Circ Physiol. 2015;309(5):H946-57.
36. Webber M, Jackson SP, Moon JC, Captur G. Myocardial fibrosis in heart failure: anti-fibrotic therapies and the role of cardiovascular magnetic resonance in drug trials. Cardiol Ther. 2020;9(2):363-76.

37. Kim BG, Cho SW, Ha JH, Ahn HS, Lee HY, Kim GS, et al. Relationship between the ST-segment resolution and microvascular dysfunction in patients who underwent primary percutaneous coronary intervention. Cardiol Res Pract. 2019:2019:8695065.

38. Ndrepepa G, Alger P, Kufner S, Mehilli J, Schomig A, Kastrati A. STsegment resolution after primary percutaneous coronary intervention in patients with acute ST-segment elevation myocardial infarction. Cardiol J. 2012;19(1):61-9.

\section{Publisher's Note}

Springer Nature remains neutral with regard to jurisdictional claims in published maps and institutional affiliations.
Ready to submit your research? Choose BMC and benefit from:

- fast, convenient online submission

- thorough peer review by experienced researchers in your field

- rapid publication on acceptance

- support for research data, including large and complex data types

- gold Open Access which fosters wider collaboration and increased citations

- maximum visibility for your research: over 100M website views per year

At BMC, research is always in progress.

Learn more biomedcentral.com/submissions 